This is the accepted manuscript of the article, which has been published in Engineering Psychology and Cognitive Ergonomics : 16th International Conference, EPCE 2019, Held as Part of the 21st HCI International Conference, HCII 2019, Orlando, FL, USA, July 2631, 2019, Proceedings. 2019, 29-38. http://dx.doi.org/10.1007/978-3-030-22507-0_3

\title{
Work fragmentation, task management practices and productivity in individual knowledge work
}

\author{
Heljä Franssila ${ }^{1}$ \\ ${ }^{1}$ Tampere University, Faculty of Information Technology and Communication Sciences (ITC), \\ FI-33014 Tampere University
}

\begin{abstract}
.
The study examined the nature of task management practices, their prevalence and relations to experiences of work fragmentation and productivity among Finnish state governmental organization employees, all of them knowledge workers. In the descriptive analysis it was found out, that knowledge workers experience most often work fragmentation as experiences of extreme hurry and forgetfulness. When considering productivity, respondents were more often satisfied with the quality of work they were able to fulfil, but less often to the amount of work they were able to finish. Less than half of the respondents collect and list all of their tasks into one place regularly. Every fifth of respondents newer plan or write down work duties and goals for the beginning work week, and every fourth of respondents never decide the start and due date for their single work tasks. Nearly every fifth never utilised any digital tool to support any personal task management activity. The correlation analysis revealed that negative correlation between the experiences of work fragmentation and productivity was statistically significant. Experiences of effectiveness of task management was negatively correlated with work fragmentation. Finally, maturity of applied task management practices was positively correlated with effectiveness of task management.
\end{abstract}

Keywords: work fragmentation, task management, productivity, knowledge work.

\section{Introduction}

Maintaining sense of coherence and satisfying levels of personal productivity in a daily basis is a challenge in hectic contemporary knowledge work life. Maintenance of smooth work flow and ability to concentrate fully in the work duties is hard. Experiences of performance losses caused by the fragmentation of work are common in contemporary knowledge work settings. Task execution and getting tasks fulfilled is hampered by both external and internal interruptions, creating a workflow containing con- 
stant and rapid task switching (Czerwinski et al. 2004, Iqbal \& Horvitz, 2007). Considerable share of external distractions originate from digital work environment (Franssila et. al, 2014). Conventional approach to support knowledge workers to maintain more productive workflow and avoid work fragmentation has concentrated on different ways interface design and application settings can protect task execution from external distractions (e.g. Iqbal \& Horvitz, 2007, Lindlbauer et. al, 2016). However, a considerable share of interruptions are self-generated (Dabbish et. al, 2011, Adler \& Benbunan-Fich, 2013). Instead, very little in known about daily task management and task execution planning practices of knowledge workers.

In order to better understand conditions and consequences of task management and task planning in individual knowledge work, this study examined the nature of task management practices, their prevalence and relations to experiences of work fragmentation and productivity among Finnish state governmental organization knowledge workers. The research questions of this study were:

1) What is the nature of work fragmentation experiences in knowledge work settings?

2) How work fragmentation is related to the experiences of task management effectiveness and personal productivity?

3) What is the nature and prevalence of task management practices applied by knowledge workers?

4) How the maturity of task management practices and experiences of task management effectiveness are related?

5) How the maturity of task management practices and experiences of work fragmentation and personal productivity are related?

\section{Background}

Despite widespread experiences of hurry, work fragmentation and interruptions in knowledge work settings, surprisingly small amount of academic research has empirically observed knowledge worker task management and task execution planning practices (Haraty et. al, 2016). In the academic literature, concepts of task management, task planning, activity planning and time management have been applied somewhat interchangeably, referring to broad categories of activities related to task planning and task scheduling (see Claessens et al., 2009). Several studies examine the complicated and overloaded role email often plays in practical task management of knowledge workers (Bellotti et al., 2005, Whittaker et al., 2007). In an interview and video-diary study observing academic professionals it was found out, that the main task management activities applied were planning, prioritization and list-making. Task management and task execution contained various challenges. In particular in task management, several difficulties were experienced: integrating different media, rearranging tasks, determining appropriate tasks, identifying reasonable timeframes, generating flexible schedules, managing long term goals, estimating task duration and differentiating the nature of different tasks. Considering actual task performance, another set of difficulties were identified: accomplishing competing tasks, undertaking planned tasks, undertaking 
long term goals, undertaking tasks that do not involve other people, remembering small tasks, retaining self-motivation and assessing previous achievements. (Kamsin, 2014). However, it was left unclear, how actively and regularly academics executed different task management activities. In another diary and survey study actual task completion of R\&D engineers was monitored. In the multi level analysis it was found out, that the tasks with higher priority, urgency and lower importance were more likely to be completed. The time management training reveiced recently was one of the individual level explainers of the task completion rate, alongside with the personality trait of conscientiousness and emotional stability. However, self-reported inclination to planning was not related to higher rate of actual task completion. (Claessens et al., 2009). On the other hand, time management training does not always quarantee actual application of learned strategies into daily work. In a study observing impact of time management training into perceived stress, perceived control of time and performance at work, large differences in the actual application of learned strategies were found. (Häfner \& Stock, 2010).

According the theory of implementation intention and goal attainment (Gollwitzer \& Oettingen, 2016), when one has explicitly specified when, where and with which sub-steps one is going to fulfil a task goal, it has tendency to become fulfilled. The basic script of specifying implementation intentions resembles the main elements of task management and task planning - deriving sub-goals and concrete task from main goals, estimating time required to complete different tasks, understanding temporal interdependencies between tasks, putting various task into order of execution, scheduling both long and short term task execution and monitoring the rate of task accomplishment. It can be hypothesized, that in knowledge work settings which are filled with variety of goals and variety of possibilities to organize one's duties, specifying implementation intentions and "scripting" one's goal attainment may enhance sense of coherence and personal productivity, and finally even eliminate the stressful experiences of work fragmentation. On the other hand, can the nature and maturity level (or lack) of task management methods and practices applied explain at least a share of concurrent experiences of work fragmentation? While several studies have evaluated and given design recommendation for specific digital tool functionalities to support task management, the overall understanding of core processes and applied practices of task management in the real world among knowledge workers has remained vague. This study provides description of the task management practices applied in knowledge work settings and provides preliminary evidence that development and deployment of task management skills can enhance knowledge worker productivity.

\section{$3 \quad$ Methodology}

The data of the study was collected with an online survey distributed to knowledge workers ( $\mathrm{n}=59$ ) employed in a governmental organization in autumn 2018. The survey was delivered to a group of volunteer participants in the organization. Variable amount 
of expert, management and support duties were included into the work roles of the survey participants. Most of the participants (95\%) had expert duties, $24 \%$ of participants had managerial duties and $22 \%$ had support duties in their task profile.

The survey contained measures to assess as dependent variables daily experiences of work fragmentation and personal productivity developed in Franssila et. al (2016). Respondents were asked to indicate their experiences in overall during the last five working days. As independent variables were measures of qualitative nature and effectiveness of applied task management practices. Measures for task management practices were designed for the purpose of this study, operationalizing the theories of implementation intention and goal striving (Gollwitzer \& Oettingen, 2016).

Measures of work fragmentation, productivity and task management effectiveness were composed of item statements, and respondents were asked to assess the item statements on 5-point rating scale, from "I strongly disagree" $(=1)$ to "I strongly agree" (=5) (see Table 1.). The final measures of work fragmentation, task management effectiveness and productivity were calculated by summing the scores of item variables according to Table 1. The reliabilities of measures were evaluated with Cronbach's alpha, and they were the following: work fragmentation $(\alpha=0,75)$, task management effectiveness $(\alpha=0,88)$ and productivity $(\alpha=0,49)$

Table 1. Description of the Survey Measures - Work Fragmentation, Task Management Effectiveness and Productivity.

\begin{tabular}{ll}
\hline Measure & $\begin{array}{l}\text { Items in the Measure (rating scale: } 1=\text { I strongly disagree...5=I } \\
\text { strongly agree.) }\end{array}$ \\
& Considering my personal work performance during the last five \\
& work days, I was experiencing... \\
Work Fragmentation & intensive hurry \\
& forgetfulness \\
& too frequent disruptive interruptions \\
& difficulties to concentrate to tasks at hand \\
& difficulties to complete tasks which I believed I could complete \\
& today \\
Task management & ease of prioritization of my daily work \\
effectiveness & ease of deciding the task execution order in my daily work \\
Productivity & satisfaction with the quality of completed work \\
& satisfaction with the amount of completed work \\
\hline
\end{tabular}

Measure of task management practices was composed of item statements considering application of various task management practices, and respondents were asked to assess the item statements on 3-point rating scale, with scores "I apply this practice 
regularly" $(=1)$, "I apply this practice time to time" $(=2)$, and "I never apply this practice" $(=3)$ (see Table 2$)$. The final measure of task management practices was calculated by summing the scores of item variables according Table 2 . The reliability of the measure of task management practices was evaluated with Cronbach's alpha, and the score was $\alpha=0,75$.

Table 2. Description of the Survey Measures - Task Management Practices.

\begin{tabular}{ll}
\hline Measure & $\begin{array}{l}\text { Items in the Measure (rating scale: "I apply this practice regu- } \\
\text { larly" (=1), "I apply this practice time to time" (=2), and "I never } \\
\text { apply this practice" (=3). }\end{array}$ \\
\hline Task management & I collect and list all my tasks into one place. \\
practices & I "take an inventory" of my tasks regularly by checking with tasks \\
are completed and which are uncompleted. & I organize and split goals of my work role and tasks into concrete \\
& subtasks. \\
& I classify my tasks according to which goals and responsibility ar- \\
& eas of my work role they serve. \\
& I examine my work task load as a whole in order to see how dif- \\
& ferent goal areas of my work role are represented there. \\
& I classify my tasks according importance. \\
& I classify my tasks according attractiveness. \\
& I classify my tasks according urgency. \\
I budget (=estimate and book) time for different tasks and for dif- \\
ferent responsibility areas of my work role. \\
I plan and record tasks and goals for the beginning work week. \\
I plan and record tasks and goals for the beginning work day. \\
I decide when I start and complete certain work task. \\
I schedule all my tasks (not only meetings and appointments) to \\
be completed in certain time.
\end{tabular}

In addition, open ended questions were included into the survey. In open ended questions, respondents were able to describe in their own words, what kind of digital tools and practices they applied in their daily task management, if any. In particular, the tools and practices applied in listing, evaluating, screening and organizing their tasks and managing time were asked to be described in the responses. From qualitative, written responses the amount of mentions of different applications and tools were recorded.

In the analysis of survey data, first, descriptive statistics of measures were calculated. Next, correlation analysis to study relations between dependent and independent variables was executed. Correlations between work fragmentation, productivity experiences and the maturity level of task management practices were statistically tested. 


\section{$4 \quad$ Results}

In the descriptive analysis it was found out, that knowledge workers experience most often work fragmentation as experiences of extreme hurry and forgetfulness, but a bit less often difficulties to complete the duties they has planned for the day (Table 3.). When considering productivity, respondents were more often satisfied with the quality of work they were able to fulfil, but less often to the amount of work they were able to finish (Table 4.). Prioritization and planning the execution order of the tasks were equally challenging task management activities (Table 5).

Table 3. Descriptive statistics of items of work fragmentation measure $(n=59)$.

\begin{tabular}{lll}
\hline Items (scale: 1 = I strongly disagree...5=I strongly agree.) & Mean & SD \\
\hline Intensive hurry & 3,66 & 0,93 \\
Forgetfulness & 3,59 & 1,00 \\
Too frequent disruptive interruptions & 3,37 & 1,05 \\
Difficulties to concentrate to tasks at hand & 3,36 & 0,99 \\
Difficulties to complete tasks which I believed I could complete today & 3,11 & 1,19 \\
& \\
\hline
\end{tabular}

Table 4. Descriptive statistics of items of productivity measure $(n=59)$.

\begin{tabular}{lll}
\hline Items (scale: $1=$ I strongly disagree...5=I strongly agree.) & Mean & SD \\
\hline Satisfaction with the quality of completed work & 3,83 & 0,56 \\
Satisfaction with the amount of completed work & 3,07 & 0,96 \\
& & \\
\hline
\end{tabular}

Table 5. Descriptive statistics of items of task management effectiveness measure $(n=59)$.

\begin{tabular}{lll}
\hline Items (scale: 1 = I strongly disagree...5=I strongly agree.) & Mean & SD \\
\hline Ease of prioritization of my daily work & 3,19 & 0,86 \\
Ease of deciding the task execution order in my daily work & 3,14 & 0,86 \\
& & \\
\hline
\end{tabular}

Analysis of responses to open ended questions revealed, that variety of distinct digital applications and functionalities were utilized in one or several distinct task management activities. Wide variety of applications were utilized in note-taking related to the task management. Tools supporting paper-mimicking note-taking and reminders (MS Onenote and Sticky Notes) were rather actively applied. Also a share (15\%) of respondents utilized the specific, integrated task management tool Outlook Tasks (Table 6). 
Table 6. Variety of digital applications utilized in task management based on open responses.

\begin{tabular}{lc}
\hline Tool / application & \% of users \\
\hline MS Outlook (in general) & 66 \\
MS Outlook Calendar & 53 \\
MS Onenote (in personal use) & 34 \\
MS Sticky Notes & 24 \\
MS Outlook Tasks & 15 \\
Project management application & 12 \\
MS Excel & 9 \\
Categories in MS Outlook & 7 \\
Trello & 5 \\
MS Outlook Email & 5 \\
MS Word & 5 \\
Kanbanflow & 5 \\
MS Planner & 3 \\
MS Onenote (in collaborative use) & 2 \\
MS Sharepoint collaboration site & 2 \\
Reminders in MS Outlook & 2 \\
Notepad & 2 \\
Windows Resource Manager & 2 \\
\end{tabular}

Nearly every fifth never utilised any digital tool to support any personal task management activity. Some of the participants utilized both paper-based and digital means to manage their tasks. In overall, it was not possible to determine, what other than digital tools were actually applied in recording and scheduling tasks. In addition, when respondent mentioned "Outlook" as an application they utilized, it is impossible to determine, which tool/tools of Outlook they were actually using.

Less than half of the respondents collect and list all of their tasks into one place regularly. Nearly every fifth of respondent newer plan or write down work duties and goals for the beginning workweek, and every fourth of respondents never decide the start and due date for their single work tasks (Table 7). 
Table 7. Descriptive statistics of items of task management practices measure $(n=59)$.

\begin{tabular}{|c|c|c|c|}
\hline Item & $\begin{array}{l}\% \\
\text { respondents } \\
\text { who never } \\
\text { apply the } \\
\text { practice }\end{array}$ & $\begin{array}{l}\% \\
\text { respondents } \\
\text { who from } \\
\text { time to time } \\
\text { apply the } \\
\text { practice }\end{array}$ & $\begin{array}{l}\% \\
\text { respondents } \\
\text { who } \\
\text { regularly } \\
\text { apply the } \\
\text { practice }\end{array}$ \\
\hline I collect and list all my tasks into one place. & 7 & 47 & 46 \\
\hline $\begin{array}{l}\text { I "take an inventory" of my tasks regularly by } \\
\text { checking with tasks are completed and which are } \\
\text { uncompleted. }\end{array}$ & 7 & 61 & 32 \\
\hline $\begin{array}{l}\text { I organize and split goals of my work role and } \\
\text { tasks into concrete subtasks. }\end{array}$ & 20 & 58 & 22 \\
\hline $\begin{array}{l}\text { I classify my tasks according to which goals and } \\
\text { responsibility areas of my work role they serve. }\end{array}$ & 64 & 28 & 9 \\
\hline $\begin{array}{l}\text { I examine my work task load as a whole in order } \\
\text { to see how different goal areas of my work role } \\
\text { are represented there. }\end{array}$ & 53 & 44 & 3 \\
\hline I classify my tasks according importance. & 5 & 39 & 56 \\
\hline I classify my tasks according attractiveness. & 55 & 41 & 3 \\
\hline I classify my tasks according urgency. & 0 & 29 & 71 \\
\hline $\begin{array}{l}\text { I budget (=estimate and book) time for different } \\
\text { tasks and for different responsibility areas of my } \\
\text { work role. }\end{array}$ & 12 & 61 & 26 \\
\hline $\begin{array}{l}\text { I plan and record tasks and goals for the beginning } \\
\text { work week. }\end{array}$ & 21 & 53 & 26 \\
\hline $\begin{array}{l}\text { I plan and record tasks and goals for the beginning } \\
\text { work day. }\end{array}$ & 15 & 58 & 27 \\
\hline $\begin{array}{l}\text { I decide when I start and complete certain work } \\
\text { task. }\end{array}$ & 27 & 56 & 17 \\
\hline $\begin{array}{l}\text { I schedule all my tasks (not only meetings and ap- } \\
\text { pointments) to be completed in certain time. }\end{array}$ & 14 & 66 & 20 \\
\hline
\end{tabular}

In the correlation analysis of measures of work fragmentation, productivity, task management effectiveness and task management practices applied it was found out, that negative correlation between the experiences of work fragmentation and productivity was statistically significant $(r=-0,430, p=0,001)$. Experiences of effectiveness of task management was negatively correlated with work fragmentation $(r=-0,451, p=0,000)$. Finally, maturity of applied task management practices was positively correlated with effectiveness of task management $(r=0,299, p=0,022)$. 


\section{Discussion}

This study was one of the first academic examinations of prevalence of task management and task planning activities in real life knowledge work context. The results of the study show, that negative experiences of work fragmentation, loss of control over task execution and lost productivity are less common among knowledge workers who proactively manage their task load, and organize and plan their task execution. When considering countermeasures to hinder productivity losses related to interruption-prone contemporary work environments, more emphasis should be put into the development of task management practices and their training and implementation among knowledge workers. When most of the knowledge work assignments are both delivered and executed in digital work environment, the skills and practices of efficient digital task management and task execution planning are critical to enhance productivity and to mitigate stress and negative mental workload created by work fragmentation.

\section{$6 \quad$ Limitations}

Because the empirical data collected in this study was based on subjective assessments on frequency of task management activities, certain bias compared to the actual practices applied may exist. Another limitation of the study is the small size of the survey data and the inclusion of only one organization into analysis.

\section{Conclusions}

Despite widespread experiences of hurry, work fragmentation and interruptions in knowledge work settings, surprisingly small amount of academic research has empirically observed knowledge worker task management and task execution planning practices (Haraty et. al (2016)). The results of this study show, that the more comprehensive the repertoire of task management practices actually applied in everyday work, the higher the experience of task management effectiveness. Further, the experience of effectiveness of task management was related to experiences of lower work fragmentation. Experiences of work fragmentation and personal productivity were related - the higher the experiences of fragmentation, the lower the experiences of personal productivity. While several studies have evaluated and given design recommendation for specific digital tool functionalities to support task management, the overall understanding of core processes and applied practices of task management in the real world among knowledge workers has remained vague. This study provided description of the task management practices applied in knowledge work settings and provides preliminary evidence that development and deployment of task management skills can enhance knowledge worker productivity. 


\section{Acknowledgements}

This study would not have been possible without the helpful Human Resources staff of the participating governmental organization and the efforts of all the survey participants. The conference presentation of this paper in HCI International 2019 -conference was supported by Finnish Work Environment Fund.

\section{$9 \quad$ References}

1. Adler, R. \& Benbunan-Fich, R. (2013) Self-interruptions in discretionary multitasking. Computers in Human Behavior, 29(4), pp. 1441-1449.

2. Bellotti, V., Ducheneaut, N., Howard, M., Smith, I, \& Grinter, R. E. (2005). Quality versus quantity: E-mail-centric task management and its relation with overload. Human-Computer Interaction, 20(1-2), 89-138.

3. Claessens, B.J., Roe, R.A. \& Rutte, C.G. (2009) Time management: logic, effectiveness and challenges. In Roe, R.A., Waller, M.J. \& Clegg, S.R. (eds.) Time in organizational research. Routledge. pp. 23-41.

4. Claessens, B. J., Van Eerde, W., Rutte, C. G. \& Roe, R. A. (2009). Things to do today...: A daily diary study on task completion at work. Applied Psychology, 59(2), 273-295.

5. Czerwinski, M., Horvitz, E. \& Wilhite, S., 2004. A diary study of task switching and interruptions. In Proceedings of the CHI 2004, ACM, pp. 175-182.

6. Dabbish, L., Mark, G. \& González, V.M. (2011) Why do i keep interrupting myself? Environment, habit and self-interruption. In Proceedings of the CHI 2011, ACM, pp. 3127-3130.

7. Franssila, H., Okkonen, J., \& Savolainen, R. (2014) Email intensity, productivity and control in the knowledge worker's performance on the desktop. In Proceedings of the 18th International Academic MindTrek Conference: Media Business, Management, Content \& Services, ACM, pp. 19-22.

8. Franssila, H., Okkonen, J., \& Savolainen, R. (2016) Developing measures for information ergonomics in knowledge work. Ergonomics, 59(3), pp. 435-448.

9. Gollwitzer, P.M. \& Oettingen, G. (2016) Planning Promotes Goal Striving. In Vohs, K \& Baumeister, R. (2016) Handbook of Self-regulation, pp. 223-244.

10. Haraty, M. \& McGrenere, J. \& Tang, C. (2016) How personal task management differs across individuals. International Journal of Human-Computer Studies, 88, pp. 13-37.

11. Häfner, A., \& Stock, A. (2010). Time management training and perceived control of time at work. The journal of psychology, 144(5), 429-447.

12. Iqbal, S.T. \& Horvitz, E. (2007) Disruption and recovery of computing tasks: Field study, analysis, and directions. In Proceedings of the CHI 2007, ACM, pp. 677-686.

13. Kamsin, A. (2014). Improving Tool Support for Personal Task Management (PTM). Doctoral dissertation, UCL (University College London).

14. Lindlbauer, D., Klemen, L., Walter, R \&, Müller, J. (2016) Influence of Display Transparency on Background Awareness and Task Performance. In Proceedings of the CHI 2016, $1705-1716$.

15.Whittaker, S., Bellotti, V. \& Gwizdka, J. (2007). Everything through Email. In Personal Information Management (pp. 167-189). University of Washington Press. 